\title{
Analysis of various types of ectopic pregnancies: a five-year review
}

\author{
Maheswari S., Poornima C.*, Lalitha N., Seetha Panicker
}

Department of Obstetrics and Gynecology, PSG Institute of Medical Sciences and Research, Tamil Nadu, India

Received: 13 April 2018

Accepted: 05 May 2018

\section{*Correspondence:}

Dr. Poornima C,

E-mail: kavint43@gmail.com

Copyright: $\odot$ the author(s), publisher and licensee Medip Academy. This is an open-access article distributed under the terms of the Creative Commons Attribution Non-Commercial License, which permits unrestricted non-commercial use, distribution, and reproduction in any medium, provided the original work is properly cited.

\section{ABSTRACT}

Background: Ectopic pregnancy (EP) is a common, life threatening emergency during the first trimester and a significant cause for maternal morbidity and mortality. In any woman of reproductive age presenting with abdominal pain and vaginal bleeding, ectopic pregnancy should be considered. The objectives of the present study is to determine the incidence, risk factors, clinical presentation, type of ectopic pregnancy, treatment, morbidity and mortality.

Methods: Retrospective analysis of case sheets of patients admitted with ectopic pregnancy at PSGIMSR, Coimbatore during the period July 2011 to June 2016 was done. The details noted were age, parity, risk factors \{previous abortion, previous EP, previous pelvic surgery, intrauterine contraceptive device, tubectomy, history of pelvic inflammatory disease \}, treatment for infertility, clinical presentation, ultrasound findings, investigations including beta HCG value and hemoglobin level, treatment offered, need for blood transfusion, operative findings and morbidity.

Results: During the five year, there were 12,407 deliveries at our hospitals and 88 cases of ectopic pregnancies were managed. The incidence is $6.6 / 1000$ deliveries. Among them $44 \%$ belonged to the age group of $25-30$ years and multi gravida were $73.8 \%$. Most common risk factors were previous abortion $(23.8 \%)$ and previous surgeries including caesarean section, tubectomy, appendicectomy, tubal microsurgery $(23.8 \%)$. Most common presentation was pain abdomen (85.2\%). Out of the 88 cases, 73 patients were managed surgically (82.9\%) and 11 cases were managed successfully with methotrexate (12.5\%). Three of them underwent conservative management and one had Uterine Artery Embolization.

Conclusions: Early diagnosis based on risk factors and timely intervention plays a main role in reducing morbidity and mortality associated with ectopic pregnancy.

Keywords: Beta HCG, Ectopic pregnancy, Methotrexate, Risk factors, Salphingectomy Transvaginal USG

\section{INTRODUCTION}

An ectopic pregnancy is implantation of fertilized ovum outside the normal endometrial cavity i.e, fallopian tube, ovary, caesarean scar, cervix and peritoneal cavity. ${ }^{1}$ In the first trimester, ectopic pregnancy is the most common cause for maternal morbidity and mortality. ${ }^{2}$ It has also been shown that EP reduces future fertility and increases the chance of subsequent EP. ${ }^{3}$ The incidence of EP is increasing since the last decade, but the incidence of complications like rupture and morbidity are declining due to early diagnosis with serial Beta-HCG(human chorionic gonadotrophin) monitoring, transvaginal USG(ultrasonogram) and minimally invasive surgery. ${ }^{4}$ Early diagnosis not only reduces the risk of tubal rupture but also allows for conservative and medical management. ${ }^{5}$ Prior damage to the fallopian tube due to PID(pelvic inflammatory disease), tubal surgeries, pelvic adhesions are the major risk factors for ectopic pregnancy. ${ }^{6}$ The other identified risk factors are, 
advanced maternal age, previous EP, previous pelvic surgeries, IUCD (intra uterine contraceptive device) insertion and infertility treatment. ${ }^{7-12}$ Identifying these risk factors among high risk mothers helps in early diagnosis and reduces the morbidity related to this condition. ${ }^{13}$ Unfortunately, most of the patients presenting with EP do not have risk factors.

\section{METHODS}

This was a retrospective analysis of case records of patients admitted with ectopic pregnancy, done at PSG IMSR Hospital, Coimbatore from July 2011 - June 2016.

\section{Inclusion criteria}

We included all the patients with suspected ectopic pregnancy who were confirmed by $\beta \mathrm{HCG}$ and transvaginal ultrasound.

\section{Exclusion criteria}

None

\section{Methodology}

The case sheets were retrieved from medical record department and the details such as age, parity, risk factors like previous abortion, previous EP, previous pelvic surgery, contraception in the form of IUCD and tubectomy, history of PID, infertility treatment, clinical presentation, investigations including beta HCG value, hemoglobin level, treatment offered, need for blood transfusion, operative findings and morbidity were collected and analyzed.

\section{Statistical analysis}

No statistical tool used.

\section{RESULTS}

During the 5-year period, there were 12,407 deliveries at our institution and 88 cases of ectopic pregnancies were managed. The incidence was 6.6/1000 deliveries. Among the patients most of them belonged to the age group of 25-30 years (Table-1). 26\% of patients were primigravida, $73.8 \%$ of patients were multigravida (Figure -1).

\section{Table 1: Age group.}

\begin{tabular}{|lll|}
\hline Age in years & Number of cases & $\%$ \\
\hline$<25$ & 22 & 25 \\
\hline $25-30$ & 39 & 44 \\
\hline $31-35$ & 18 & 20 \\
\hline $36-40$ & 5 & 5.6 \\
\hline$>41$ & 4 & 4.5 \\
\hline
\end{tabular}

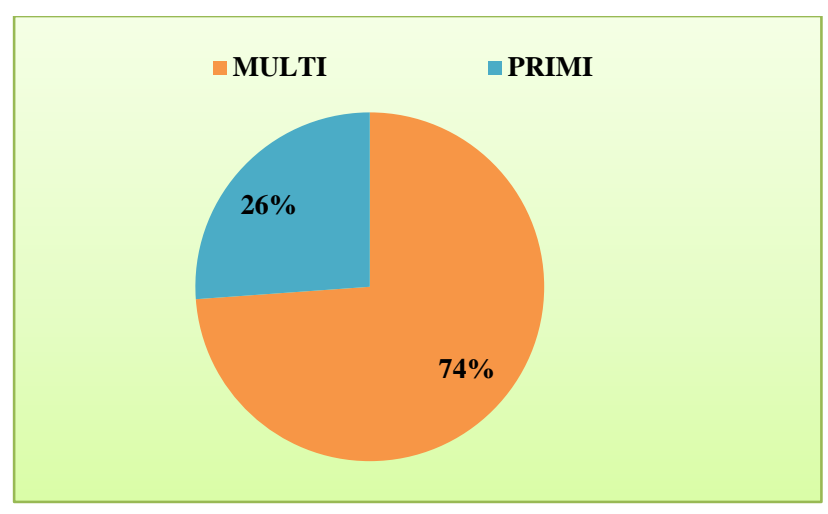

Figure 1: Sonographic pattern of relative risk of abnormal Doppler.

As shown in (Table 2) $23.8 \%$ of patients had one or more spontaneous or induced abortions. $23.8 \%$ of patients had undergone pelvic surgery (Caesarean section, tubectomy appendicectomy, tubal recanalistion). PID and previous ectopic pregnancy accounted for $4.5 \%$ each.

Table 2: Risk factors.

\begin{tabular}{|lll|}
\hline Risk factors & Number of cases & $\%$ \\
\hline Previous abortion & 21 & 23.8 \\
\hline Previous surgeries & & \\
\hline Caesarean section & 21 & 23.8 \\
\hline Tubectomy & 14 & 15.9 \\
\hline Appendicectomy & 3 & 3.4 \\
\hline Tubal recanalistion & 2 & 2.2 \\
\hline Ovulation induction & 7 & 7.9 \\
\hline Contraception & & \\
\hline IUCD insertion & 6 & 6.8 \\
\hline PID & 4 & 4.5 \\
\hline Previous ectopic & 4 & 4.5 \\
\hline
\end{tabular}

Commonest presenting complaint was pain abdomen in $85.2 \%$ of patients. Other presenting complaints were Amenorrhoea in $68 \%$ and vaginal bleeding in $59 \%$ (Table-3).

Table 3: Presenting symptoms.

\begin{tabular}{|lll|}
\hline Symptom & Number of cases & $\%$ \\
\hline Pain & 75 & 85.2 \\
\hline Amenorrhea & 60 & 68.1 \\
\hline Bleeding PV & 52 & 59 \\
\hline
\end{tabular}

Most of them presented between 5-8 weeks of gestational age $(61.3 \%) .27 .2 \%$ of patients were diagnosed before 4 weeks of amenorrhea and $11.3 \%$ were above 9 weeks. All the cases had been confirmed by USG.17 of them had Beta-HCG less than $1000 \mathrm{~m} \mathrm{I} \mathrm{U} \mathrm{/ml.} \mathrm{A} \mathrm{patient} \mathrm{with}$ heterotopic pregnancy had Beta -HCG of more than 1 lakh $\mathrm{m} \mathrm{I} \mathrm{U} \mathrm{/ml.}$

Commonest site of ectopic pregnancy was fallopian tube in $93 \%$ of patients (Table 4 ). 
Table 4: Site of ectopic pregnancy.

\begin{tabular}{|lll|}
\hline Site of ectopic & Number of cases & $\%$ \\
\hline Tube & 82 & 93 \\
\hline Caesarean scar & 3 & 3.4 \\
\hline Ovary & 2 & 2.4 \\
\hline Heterotopic & 1 & 1 \\
\hline
\end{tabular}

The commonest site of tubal involvement was in ampulla (Table 5).

Table 5: Site of tubal involvement

\begin{tabular}{|lll|}
\hline Tubal site & Number of cases & $\%$ \\
\hline Ampulla & 60 & 73.1 \\
\hline Cornua & 10 & 12.1 \\
\hline Isthmus & 6 & 7.3 \\
\hline Fimbria & 4 & 4.8 \\
\hline Tubal abortion & 2 & 2.4 \\
\hline
\end{tabular}

On receiving, $86 \%$ of patients were hemodynamically stable, $13.6 \%$ of patients were in various stages of shock. $53.6 \%$ of patients presented with ruptured ectopic, unruptured ectopic was noted in $43.9 \%$ of patients (Table $6)$.

Table 6: Condition of tube.

\begin{tabular}{|lll|}
\hline Condition of tube & Number of cases & $\%$ \\
\hline Ruptured & 44 & 53.6 \\
\hline Unruptured & 36 & 43.9 \\
\hline Tubal abortion & 2 & 2.5 \\
\hline
\end{tabular}

Right sided tubal ectopic was noted in $65.8 \%$, left side tube involved in $34.1 \%$ of patients. Tubal abortion was observed in $2.5 \%$ of patients. Intra-operatively hemoperitoneum was noted in $64 \%$ of patients. Most common treatment offered for tubal ectopic was surgical, i.e. salpingectomy (Table 7).

\section{Table 7: Treatment.}

\begin{tabular}{|lll|}
\hline Treatment & Number of cases & $\%$ \\
\hline Medical & 11 & 12.5 \\
\hline Surgical & & \\
\hline Laparotomy & 49 & 59.7 \\
\hline Laparoscopy & 9 & 10.9 \\
\hline Medical failed & & \\
\hline Laparotomy & 8 & 9.7 \\
\hline Laparoscopy & 2 & 2.4 \\
\hline Conservative & 3 & 3.6 \\
\hline
\end{tabular}

Twenty-one patients were fit into medical management, among them $12.5 \%$ of patients were managed medically with methotrexate successfully.

10 cases failed to medical management which were subsequently managed with either laparoscopic or laparotomy and salphingectomy.
3 cases were managed conservatively by observing the declining trend of Beta-HCG.

\section{Other types of ectopic}

Caesarean scar pregnancy was diagnosed in 3 patients, among them 2 patients underwent surgical excision. One patient was managed with UAE (uterine artery embolisation) followed by methotrexate. Heterotopic pregnancy following ovulation induction which resulted in twin intra uterine gestation and tubal ectopic was noted in one patient and she underwent emergency laparotomy and salpingectomy. Two patients were diagnosed as having ovarian ectopic and surgical excision was offered to both of them. Most common morbidity noted was anemia in $42 \%$, out of which severe anemia (4-7gm) was seen in $5.6 \%$ (Table 8 ). Among them $28.4 \%$ of patients received blood and blood products. No surgical site infection or mortality was noted.

Table 8: Hemoglobin level on admission.

\begin{tabular}{|lll|}
\hline Hemoglobin level & Number of cases & $\%$ \\
\hline $4-7 \mathrm{gm} / \mathrm{dl}$ & 5 & 5.6 \\
\hline $7-10 \mathrm{gm} / \mathrm{dl}$ & 32 & 36.3 \\
$>10 \mathrm{gm} / \mathrm{dl}$ & 51 & 58.1 \\
\hline
\end{tabular}

\section{DISCUSSION}

The incidence of ectopic pregnancy among women attending emergency department with first trimester abdominal pain, bleeding or both is between 6-16 \%(14). A study conducted by Shraddha Shetty et al had incidence of $5.6 / 1000$ deliveries. ${ }^{15}$ In our study the incidence is $6.6 \% / 1000$ deliveries which is comparable. Majority of patients were between 25-30years which is similar to the above study and Khaleeqe et al. ${ }^{15,16}$

As in Karki et al (17), we had similar higher incidence of ectopic pregnancies (73.8\%) in multigravida. In our study, the commonest predisposing factors were previous abortion either spontaneous or induced, previous pelvic surgeries including caesarean section, history of IUCD insertion, tubectomy, history of PID and infertility treatment, which are similar to various other studies. ${ }^{17,18}$ As in the studies by Porwal Sanjay et al, Shraddha Shetty et al, the most common symptom in our series was pain abdomen which is comparable. ${ }^{15,18}$

Urinary beta HCG, serum beta HCG, transvaginal USG are the diagnostic tools for diagnosing EP. USG should be the investigation of choice for symptomatic women. In asymptomatic women, serial monitoring of serum beta HCG should be done. As in the study by Shraddha Shetty et al, we also had more number of right sided EP and involvement of the ampullary portion of the tube. ${ }^{15}$

Heterotopic pregnancy is rare in natural conception which is around 1 in 30,000 pregnancies. But the incidence is more in case of ovulation induction or with 
assisted reproduction techniques. In our study, we had a case of triplet heterotopic pregnancy following ovulation induction with clomiphene citrate. It is recommended that even patients shown on ultrasound to have intrauterine pregnancy should be given comprehensive pelvic ultrasound so that possibility of synchronous heterotopic pregnancy can be excluded, particularly in pregnancies following fertility treatment. ${ }^{19}$

In our study, ruptured EP was noted in $53 \%$ of cases, $43.9 \%$ of cases had an unruptured ectopic gestation. In Latchaw $G$ et al study, the same were $59 \%$ and $41 \%$ respectively. ${ }^{20}$

Laparoscopy and medical therapy have now emerged as the widely used therapeutic modalities with great success in terms of reduced morbidity, shorter hospital stay and conservation of fertility. ${ }^{21}$ However choice depends upon early identification of ectopic pregnancy and hemodynamic status of the patients. ${ }^{22}$ In our study, $11 \%$ of patients responded well to single dose of methotrexate.

Surgery should be the treatment of choice in unstable patient. ${ }^{19}$ In our study $13.6 \%$ were unstable and all of them were managed surgically. Commonest surgery performed was partial/total salpingectomy. We did bilateral total salpingectomy for patients who had undergone tubectomy previously and were not desirous of future childbearing. It has been extensively studied and reported that conservative management does not increase the risk of future ectopic. ${ }^{15}$ In our study, three patients were managed conservatively by observing the declining trend of Beta HCG. Morbidity included anemia, blood transfusion and wound infection. In our study, we had $42 \%$ of patients with hemoglobin level of less than 10 grams. Among them $28.4 \%$ of patients received blood and blood products. No surgical site wound infection was noted.

No maternal mortality was noted in our study which is consistent with the study by A Abbas et al. ${ }^{23}$ Early identification of the patients with EP by a multipronged approach including high index of suspicion, risk prediction, serum beta HCG and transvaginal ultrasound helps in improving the prognosis as far as morbidity, mortality and future fertility are concerned. ${ }^{24}$

\section{CONCLUSION}

Identification of underlying risk factors, early diagnosis with essential investigating modalities like beta-HCG, transvaginal USG, timely intervention with medical or surgical method will definitely reduce morbidity and mortality and improve the future reproductive outcome.

\section{Funding: No funding sources} Conflict of interest: None declared

Ethical approval: The study was approved by the Institutional Ethics Committee

\section{REFERENCES}

1. Walker JJ. Ectopic pregnancy. Clin Obstet Gynecol. 2007;50:89-99.

2. Mahboob U, Mazhar SB. Management of ectopic pregnancy: a two-year study. J Ayub Med Coll Abbottabad. 2006;18:34-7

3. Chow WH, Daling JR, Cates WJ, Greenberg RS. Epidemiology of ectopic pregnancy. Epidemiol Rev. 1987;9:70-94.

4. Karaer A, Avsar FA, Batioglu S. Risk factors for ectopic pregnancy: a case-control study. Aust N Z J Obstet Gynaecol. 2006;46:521-7.

5. Barnhart KT. Clinical practice. Ectopic pregnancy. N Engl J Med. 2009;361:379-87.

6. Akande V, Turner C, Horner P, Horne A, Pacey A, British Fertility Society. Impact of Chlamydia trachomatis in the reproductive setting: British Fertility Society Guidelines for practice. Human Fertil. 2010;13:115-25.

7. Job-Spira N, Collet P, Coste J, Bremond A, Laumon B. Risk factors for ectopic pregnancy. Results of a case control study in the Rhone-Alpes region. Contracept Fertil Sex. 1993;21:307-12.

8. Bouyer J, Coste J, Shojaei T, Pouly JL, Fernandez H, Gerbaud L, et al. Risk factors for ectopic pregnancy: a comprehensive analysis based on a large casecontrol, population-based study in France. Am J Epidemiol. 2003;157:185-94.

9. Parashi S, Moukhah S, Ashrafi M. Main risk factors for ectopic pregnancy: a case-control study in a sample of Iranian women. Int J Fertil Steril. 2014; 8:147-54.

10. Moini A, Hosseini R, Jahangiri N, Shiva M, Akhoond MR. Risk factors for ectopic pregnancy: a case-control study. J Res Med Sci. 2014; 19:844-9.

11. Ankum WM, Mol BW, Van der Veen F, Bossuyt PM. Risk factors for ectopic pregnancy: a metaanalysis. Fertil Steril. 1996;65:1093-9.

12. Barnhart KT, Sammel MD, Gracia CR, Chittams J, Hummel AC, Shaunik A. Risk factors for ectopic pregnancy in women with symptomatic firsttrimester pregnancies. Fertil Steril. 2006;86:36-43.

13. Timmerman D. Predictive models for the early diagnosis of ectopic pregnancy.Verh $\mathrm{K}$ Acad Geneeskd Belg. 2004;66:155-71.

14. Murray H, Baakdah $\mathrm{H}$, Bardell $\mathrm{T}$, Tulandi $\mathrm{T}$. Diagnosis and treatment of ectopic pregnancy. CMAJ. 2005; 173:905.

15. Shetty KS, Shetty KA. A clinical study of ectopic pregnancies in atertiary care hospital of Mangalore, India. Innovat J Med H Sci. 2014;4:305-9.

16. Khaleeque F, Siddiqui RI, Jafarey SN. Ectopic pregnancies: A Three-year study. J Pak Med Assoc 2001;51:240-3.

17. Karki RCL, Pradhan B, Duwa S. Annual Analysis of Ectopic Pregnancy in Tertiary Care Hospital. PMJN. 2011;11:5-8

18. Gupta R, Porwal S, Swarnkar M, Sharma N, Maheshwari P. Incidence, trends and risk factors for 
Ectopic Pregnancies in a tertiary care hospital of Rajasthan. JPBMS. 2012;16:1-3.

19. Maheswari S, Panicker S. Triplet heterotopic pregnancy following ovulation induction with clomiphene citrate: a case report and review of literature Int J Rerod Contracept Obstet Gynecol. 2013;2:743-5.

20. Latchaw G, Takacs P, Gaitan L, Geren S, Burzawa J. Risk factors associated with the rupture of tubal ectopic pregnancy. GynecolObstet Invest. 2005;60:177-80.

21. Jurkovie D. Ectopic pregnancy. In: Edmonds DK, editor. Dew Hurst's textbook of Obstetrics and Gynecology. 7 ed. USA; Blackwell Publishers;2007

22. Shah N, Khan NH. Ectopic pregnancy: Presentation and risk factors. J Coll Physicians Surg Pak. 2005; 15:535-8.
23. Abbas A, Akram H. Ectopic Pregnancy; Audit at Maula Bakhsh Teaching Hospital Sargodha.Prof Med J. 2011;18:24-7.

24. Lozeau AM, Potter B. Diagnosis and management of ectopic pregnancy. Am Fam Physician. 2005; 72:1707-14.

25. Majhi AK, Roy N, Karmakar KS, Banerjee PK. Ectopic pregnancy--an analysis of 180 cases. J Indian Med Assoc. 2007;105:308-10.

Cite this article as: Maheswari S, Poornima C, Lalitha N, Panicker S. Analysis of various types of ectopic pregnancies: a five-year review. Int J Reprod Contracept Obstet Gynecol 2018;7:2410-4. 